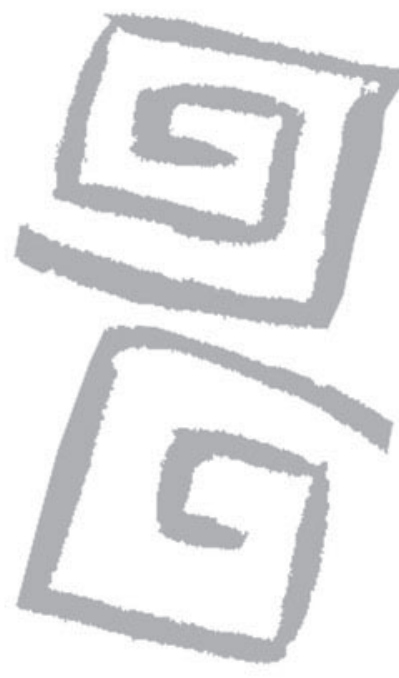

\title{
La vejez en los textos de lectura de la escuela primaria: un recorrido entre fines del siglo XIX y los inicios del siglo XXI en Argentina
}

\author{
Old age in primary school readers: a journey through \\ the end of the $19^{\text {th }}$ century to the start of the $21^{\text {st }}$ \\ century in Argentina
}

Oddone, María Julieta ${ }^{1}$

'Licenciada en Sociología, Doctora en Antropología. Investigadora, Consejo Nacional de Investigaciones Científicas y Técnicas (CONICET). Directora del Programa Envejecimiento y Sociedad, Facultad Latinoamericana de Ciencias Sociales (FLACSO). Profesora Titular, Universidad de Buenos Aires. Argentina. mjoddone@retina.ar
RESUMEN En este artículo se presenta el análisis de contenido (discurso) de los mensajes emitidos por los libros de lectura para la escuela primaria editados en Argentina, en el período comprendido entre los años 1880 y 2012. Este estudio nos permitió profundizar sobre la imagen de la vejez y el envejecimiento que la sociedad tiene y transmite a las nuevas generaciones y el papel que se le asigna a este grupo generacional. Los períodos históricos que dan contexto a los datos fueron definidos a partir de los ritmos marcados por la permanencia o los puntos de cambio (tourning point) de los valores sociales transmitidos en las lecturas. El papel asignado a los ancianos y la imagen de viejo que la sociedad argentina transmitió y transmite a las generaciones jóvenes muestra que cada período descripto tiene su propio modelo de anciano.

PALABRAS CLAVES Envejecimiento; Valores Sociales; Relaciones Intergeneracionales; Libros de Texto; Argentina.

ABSTRACT This article presents the content (discourse) analysis of messages transmitted by primary school readers in the period between 1880 to 2012. This study allowed us to explore the image of old age and aging that society has and passes on to new generations as well as the role assigned to this generational group. The historical periods that provide the context for the data were defined according to the continuity of or the turning points in the social values transmitted in the reading materials. The role assigned to elderly people and the image of old age that the Argentine society passed on and continues to pass on to younger generations demonstrate that each period described has its own model of aging.

KEY WORDS Aging; Social Values; Intergenerational Relations; Textbooks; Argentina. 


\section{INTRODUCCIÓN}

El artículo aquí presentado es una continuación y actualización de los trabajos "Los medios de comunicación social y la imagen de vejez: los libros utilizados en la escuela primaria" (1), del año 1983, y "La vejez en la educación básica argentina" (2) del año 1998. En el primero, se trabajó el período correspondiente a los años 1880 y 1980 y, en el segundo, se incorporó el análisis de los textos hasta el año 1997. En esta oportunidad se ha continuado la investigación incorporando a sus resultados datos que llegan hasta el año 2012; también se añaden imágenes y fotos que completan el análisis de los textos.

En esta investigación, que hemos emprendido hace ya muchos años y que continuamos en el transcurso del tiempo, hemos partido de la idea de que el lenguaje no es solo una premisa importante de la acción social, en la medida en que esta descansa sobre la comunicación de significados, sino que el hablar y el escribir son también por sí mismos una forma de conducta social. En lo que los hombres dicen o escriben se expresan sus intenciones, sus actitudes, su interpretación de la situación, sus conocimientos y sus supuestos tácitos sobre el entorno.

Estas intenciones y actitudes vienen codeterminadas por el sistema sociocultural al que pertenecen las personas que han dicho o escrito algo $y$, por ello, no solo reflejan las características personales de los autores, sino también los atributos de la sociedad que los rodea (normas, valores y definiciones de situaciones socialmente establecidas, entre otros atributos). Por esta razón, el análisis de materiales lingüísticos permite hacer inferencia de fenómenos no lingüísticos, tanto individuales como sociales.

En la vida cotidiana, el análisis de contenido permite a las personas comprender los significados y obtener inferencia a partir de lo dicho o escrito. Este fenómeno intuitivo para entender el lenguaje debe convertirse en objeto de análisis científico sistematizado y objetivado. En este contexto, se puede definir al análisis de contenido como una técnica de investigación que describe de una manera objetiva y sistemática propiedades de los actores y de los agregados sociales. En este sentido, el texto puede ser tanto un escrito como un discurso oral y, más ampliamente, el análisis de contenido se puede utilizar con materiales que no sean puramente lingüísticos tales como las imágenes.

En este escrito se presenta el análisis efectuado sobre las lecturas de libros utilizados, sobre todo, en el segundo grado de escolaridad primaria a nivel nacional y, de estos, se seleccionaron aquellos más usados en las escuelas dependientes del Estado. Consideramos que la sociedad transmite sistemáticamente su pensamiento e ideología a las nuevas generaciones a través de estos medios. De este modo, el análisis de contenido (discurso) de los mensajes emitidos por los libros de lectura para la escuela primaria correspondientes al período comprendido entre los años 1880 y 2012 nos permite profundizar sobre el tema de la vejez, en relación con la imagen que tiene y transmite la sociedad y el papel que se le asigna a este grupo generacional.

Los períodos históricos que dan contexto a los datos fueron definidos a partir de los ritmos marcados por la permanencia o los puntos de cambio (tourning point) de los valores sociales transmitidos en las lecturas.

\section{FINES DEL SIGLO XIX Y COMIENZOS DEL SIGLO XX (a)}

En función del contexto político y social de fines del siglo XIX, en este período se transmiten los valores de la Argentina agroexportadora y los ideales liberales de la denominada Generación del 80. Veamos:

La Argentina es un país grande, poderoso y bello [...] Nuestros campos son inmensos, y a la par que sustentan los rebaños más numerosos de la tierra abren su seno y brindan espléndidas cosechas a todos los hombres trabajadores que quieran formar un hogar tranquilo en esta tierra de libertad.

Entre nosotros reina la igualdad más absoluta y no existen más distinciones que las que naturalmente originan la virtud, la ilustración y el talento. (3) [cursivas añadidas]

Se transmite como grandes virtudes la dedicación al trabajo y al ahorro, las que sumadas a 
la honradez permiten obtener fortuna y progreso. Ahorrar permitiría tener una vejez tranquila en un contexto histórico donde no existía la jubilación.

El amor a la patria y el orgullo de morir por ella se expresan como valores en el texto. De esta manera la muerte puede ser fecunda y es por ello que se recuerdan vívidamente los hechos acaecidos en la guerra del Paraguay y, en consecuencia, se debe respeto y admiración a los veteranos sobrevivientes de esa épica.

Más cercanamente, en la década de 1930, se observan algunos cambios en los mensajes ligados a la idea de "gobernar es poblar", ya que se ha concretado el fenómeno masivo de la inmigración europea mientras que se mantienen los valores liberales de la generación de 1880: "La tierra argentina, es tierra de libertad e igualdad para quien la trabaja" (5 p.98).

El trabajo aparece como garantía de ascenso social, lo que es válido en especial para el europeo que Ilega "linyera" y asciende hasta lograr con su trabajo el lugar de "estanciero".

Recordó que muchos extranjeros habían llegado sin otra cosa que la ropa puesta. Pero como eran laboriosos y de buenas costumbres habían buscado una ocupación por todos los caminos de esta grande y linda República Argentina. Se habían radicado luego, y, al amparo de las buenas leyes, habían labrado su fortuna y la felicidad de sus hijos. (5 p.99)

Don Juan Cardona, inmigrante de ayer, y poderoso capitalista hoy, prueba prácticamente que la perseverancia y honradez, a la par de la inteligencia y del ahorro son factores tan poderosos como las alas que llevan a la cumbre. (5 p.188)

Fue la conquista del desierto, hecha por criollos, la que inició la civilización y el progreso que debían continuar los inmigrantes con la ayuda de las leyes (b).

Al focalizar en el tema de la vejez, vemos que aparece como uno de los tópicos centrales, tanto por la cantidad de apariciones como por la profundidad de las reflexiones que muestran las lecturas. En efecto, en esta época se observan matices ricos y variados para el análisis de la vejez y del proceso de envejecimiento. En los libros de lectura es común ver a personas ancianas ocupando diversos roles y colocadas en situaciones donde transmiten las normas sociales de la época basadas en la tradición y en la experiencia. Además se pueden leer en los textos reflexiones profundas sobre el tema.

En las lecturas, el anciano es fuente de respeto, aún en situaciones de marginalidad social como es el caso de los "pobres viejos abandonados", tal como se puede ver en el ejercicio de redacción de la Figura 1.

En este período, para referirse al adulto mayor, se utiliza fundamentalmente la palabra anciano. La palabra viejo es utilizada como adjetivo calificativo y no es considerada en forma peyorativa. Es decir, no hay una connotación negativa ante las palabras viejo o vieja.

$$
-46-
$$
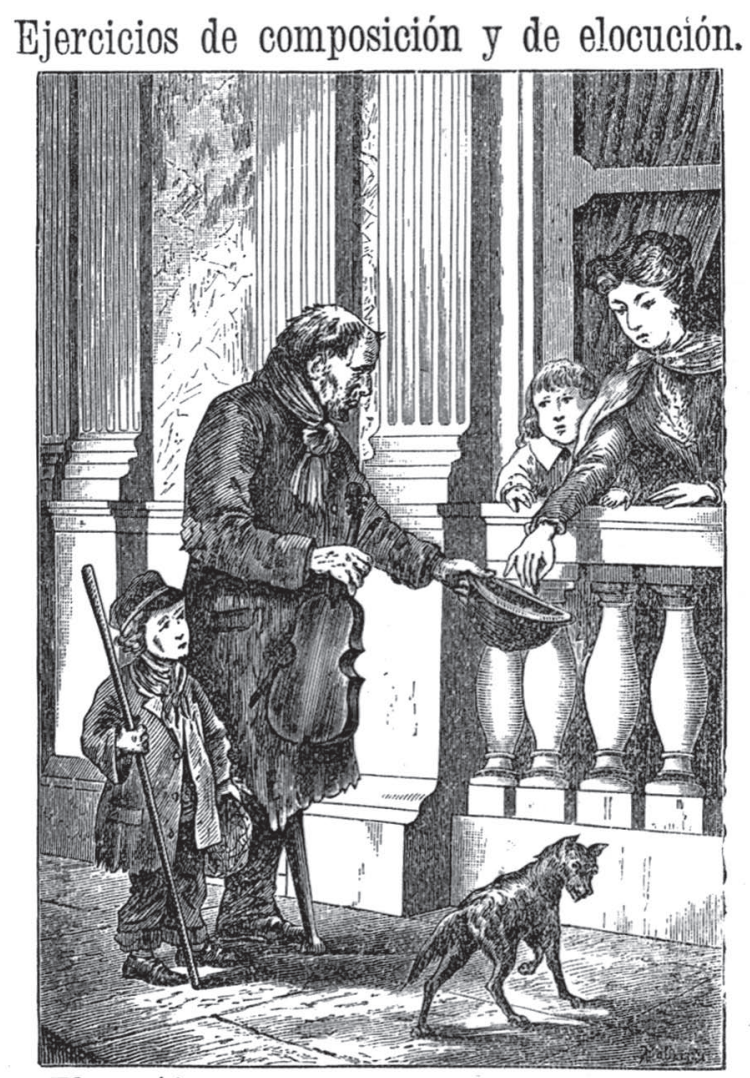

Elocución = Describir la escena representada en la lámina. mencionando todas las figuras. Indicar lo que parece pensar ó sentir cada uno de ellos, deduciéndolo de su actitud y de la expresión de su rostro = Formular algun pensamiento sobre la suerte de los pobres
viejos abandonados.

Composición = Redactarla, tomando como asunto el de $k$ presente lámina.

Figura 1. La vejez en la primera década del siglo XX. Libro de lectura escolar El nene.

Fuente: Andrés Ferreyra y José María Abuin (3 p.46). 


\section{$-116-$}

Ejercicios de elocución y de composición.

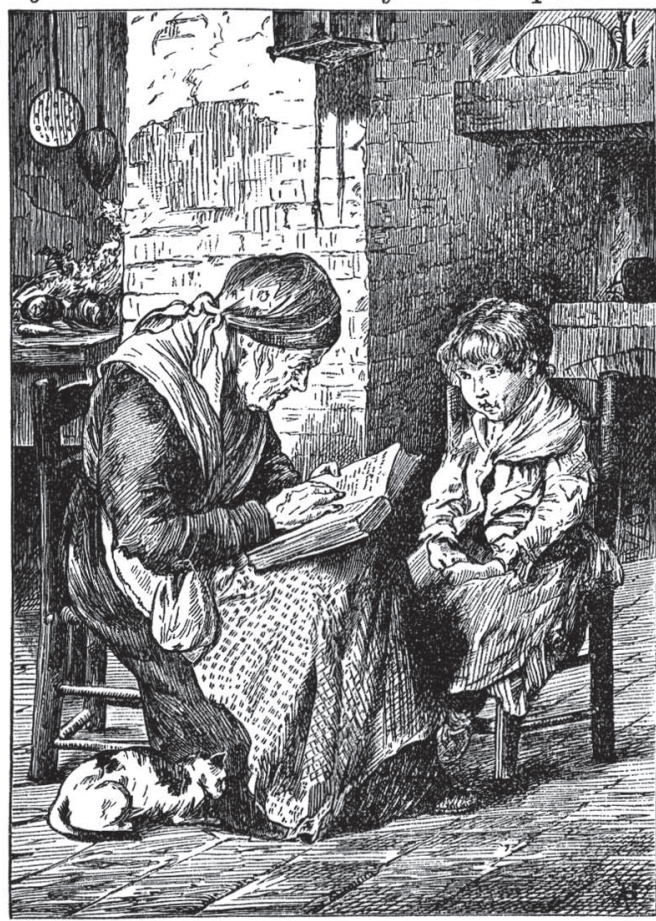

Elocución = Descripción de la escena, indicando que paren tesco pueden tener los personajes que en ella intervienen, y la aetitud y expresión de cada uno.
peto debido á los ancianos.

Composición=Redactarla, tomando por sujeto el de la láminaw

Figura 2. La vejez en la primera década del siglo XX. Libro de lectura escolar El nene.

Fuente: Andrés Ferreyra y José María Abuin (3 p.116).

El tipo de familia predominante es la extensa, definida como aquella familia en la que conviven tres o más generaciones, se envejece en familia y parece normal que los hijos se hagan cargo de sus familiares ancianos.

Distintos modelos de personas mayores aparecen a lo largo de las lecturas de los textos estudiados; en su papel de consejero-patriarca (3) el adulto mayor ocupa distintos roles tales como un veterano de guerra, un viejo sirviente, un viejo maestro, etc., y es aquel que cumple con las funciones de educador y transmisor de los valores fundamentales que, en la Argentina de principios del siglo XX, son: el amor por la patria y por los padres, la importancia de la educación como necesaria para el progreso sostenido de la nación, el respeto debido a los mayores. En cuanto a este último tema, conlleva la aceptación -sin discusión- tanto de los consejos ofrecidos por el anciano al niño como de la protección que el niño debe ofrecer a los mayores. Aquí debemos hacer notar que el rol de transmisor de valores culturales es ocupado fundamentalmente por varones que siguen claramente los paradigmas tradicionales de roles de género.

En el rol de abuelo, el anciano aparece en compañía de sus nietos, ya sea en una actividad de entretenimiento o de juego (las abuelas), ya sea brindando un sabio consejo (los abuelos) o sintiendo su trascendencia a través de las nuevas generaciones (los nietos). Es común, en esta época, que se remarque ese rol familiar de los adultos mayores ya que la cohabitación facilita la relación abuelo-nieto, lo que produce a nivel individual una menor angustia de muerte. La existencia de hijos y nietos garantiza la continuidad del apellido y de la sangre: "si el árbol que planto hoy, lo utilizan mis nietos mañana". Se trata del arquetipo muerte-nacimiento, que permitiría a todo individuo prepararse mejor para la muerte (Figura 2).

Para los ancianos pobres no hay posibilidad de retiro voluntario que, hasta el siglo XIX, será privativo de los privilegiados. El pobre debe continuar trabajando mientras sus fuerzas se lo permitan. Después, la comunidad familiar lo mantendrá como pueda. Pero si por desgracia está solo, se ve inmediatamente situado en la categoría de mendigo. Incluido en la masa de los "pobres" el anciano no se diferencia de sus compañeros de infortunio: pertenece a la historia más general de la pobreza. Muchos de los trabajadores que ocupaban posiciones laborales de nivel bajo, cuando enfermaban o envejecían, debieron recurrir a la mendicidad para sobrevivir. Esto era frecuente en la época y se observa en la imagen del anciano mendigo (3 p.46), donde se ofrece una ayuda monetaria al viejo, creando así una conciencia de caridad con el fin de paliar este problema social ya que, en ese período histórico, la solución es individual y no objeto de la política social (c).

La lectura titulada "Los ancianos" (3) que exponemos en los próximos párrafos, presenta reflexiones sobre la vejez y la muerte que no se hallarán en los períodos siguientes sino hasta los inicios del presente siglo donde estas cuestiones se retoman, por ejemplo, en la lectura "Sandía. Maestro guardián" (7), es decir que tendrán que 
pasar casi cien años para que la reflexión sobre el proceso de envejecimiento y la sucesión de las generaciones vuelva a ser incorporada en la transmisión de conocimientos escolares.

Volviendo al tema que nos ocupa, dice la lectura:

Nadie es más respetable que un anciano. Sus cabellos blancos son corona de una existencia; su cuerpo inclinado es la prueba de una misión cumplida, y su mirada, dulce y tranquila, es propia de los que ya, a las puertas de la muerte, ven de un modo claro y evidente la aurora de esa nueva vida que se Ilama eternidad.

La frente del anciano suele ser el espejo donde el joven lee o vislumbra las experiencias de la vida.

Todos nos descubrimos cuando encontramos al paso un veterano en cuyo rostro ha dejado huella el hierro enemigo.

Al contemplarle, evocamos las batallas en que ha de haberse encontrado y no fingimos los peligros que ha de haber corrido.

Un anciano es un veterano de la vida; ha sufrido desgracias, penas sin cuento; ha visto morir a los seres a quienes amaba; ha visto quizá triste y solitario su hogar; y sin embargo, no ha desesperado, ha pensado que la vida es pasajera y que el término de toda pena está en el más allá, en el seno de Dios.

¡Oh niño, que empiezas a recorrer el camino de la vida! Si alguna vez encuentras a tu paso a un anciano, salúdale cortés; si le ves sin fuerza para seguir su camino, préstale tu brazo; si le miras sin consuelo, sé piadoso, calma su pena y enjuga sus lágrimas.

Hónrale y respétale; y ante él, permanece en pie y con la cabeza desnuda. En su presencia, piensa en tus abuelos, en tus padres y en todos aquellos a quienes debes amor, protección y cuidados; y piensa, sobre todo, que tal cual es él hoy, así serás tú mañana. Se amortiguará tu energía, blanqueará tu cabeza, se desvanecerán tus esperanzas y ambiciones y serás cual él: un ser desvalido y sin fuerzas, sin más escudo que el que te presten el respeto, el cariño y la veneración de los que empiecen a gozar de la vida, cuando tu estés en el umbral de la eterna y pálida muerte. (3 p.114-115)
En esta lectura se reflexiona sobre el proceso de envejecimiento y la antesala de la muerte que significa la vejez, fomentándose la religiosidad como paso a la eternidad y calmante de la ansiedad que produce la conciencia de muerte.

Vemos además, que la imagen de vejez que se transmite no es la de una vejez activa sino que, por el contrario, tiende a ser representada como "un pobre viejo", débil, enfermizo y pasivo; pero debe ser y es respetado, y son seguidos sus consejos. La vitalidad del anciano está allí, en su experiencia, el ser físico desaparece en cuanto tal. Lejos de ser un estigma, el cuerpo gastado es un signo de respeto (Figura 3).

En síntesis, el anciano debe ser respetado por ser un hombre que vivió, y que espera la muerte, por ser un predecesor, porque es la futura imagen del niño, porque los años le dieron experiencia y esta vale en la sociedad agroexportadora de principios de 1900, donde se repetirá lo existente. Aparece como transmisor de los valores fundamentales, aquellos que siempre existieron y existirán, lo que lo convierte en un arquetipo de la sustentación de la cultura. Cumple con el rol familiar de abuelo, pero es más que eso, dicta y transmite valores, lo que le permite cumplir con una función social: tiene cabida en la sociedad.

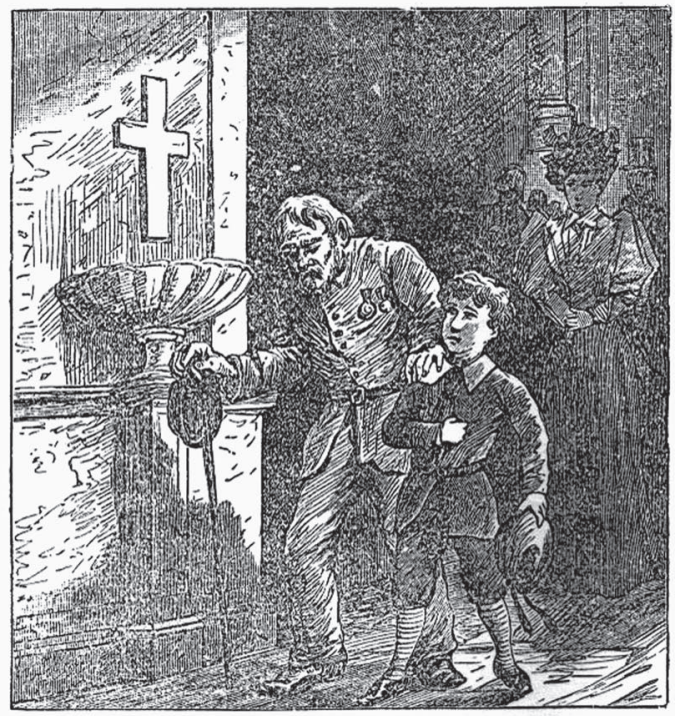

Los ancianos.

Figura 3. La vejez en la primera década del siglo XX. Libro de lectura escolar El nene.

Fuente: Andrés Ferreyra y José María Abuin (3 p.114). 
También se observa al viejo inmigrante como un hombre sabio, educado, que transmite valores fundamentales tanto en el seno de la comunidad rural como en la familia, siendo altamente valorados sus consejos y su palabra respetada y obedecida en ambos contextos.

Los valores que transmiten los ancianos son "universales": humildad, caridad, trabajo, ahorro, honradez, respeto a los mayores. Por esta razón no se oponen ni se contradicen entre las culturas propias de nativos e inmigrantes.

\footnotetext{
No hay que despreciar al pasado. El pasado no es siempre lo inútil. Es cierto que los viejos no podemos arar, pero no impide ello que aconsejemos el modo de hacerlo. La vejez que se honró en las labores, es una página nutrida de experiencia. Verdad que yo no soy capaz de correr con estas piernas achacosas, pero le puedo indicar a Humberto por donde conviene ir. (5 p.95) [cursivas añadidas]
}

Tiene peso real en el seno de la familia extensa: se le informa, consulta y opina sobre los acontecimientos del quehacer familiar (d).

En cuanto a las "reflexiones sobre la vejez, vemos que el anciano angustiado por la cercana muerte, trascenderá en los niños a través de ser el ejemplo de experiencia" (5 p.148). En el texto, el objetivo de la lectura "Vida y ensueño" que está referida a estas reflexiones se simboliza en el aforismo siguiente: "La ancianidad venerable es siempre una página de historia o un ejemplo de experiencia que conviene a la niñez" (5).

Los lugares asignados a los viejos en los textos de lectura seguirán vigentes hasta la década de 1940. Observamos que el papel que se asigna a los viejos les exige ser sensatos, sin errores ni debilidad. El anciano tiene que ser un santo, condenado a ser venerado, no tiene derecho a cometer el mínimo error; él, que tanta experiencia tiene, ya no puede sucumbir a la mínima tentación; él, tan consumido y arrugado como está, tiene que ser perfecto, ejemplo de todas las virtudes. La imagen sublimada que se les ofrece de ellos mismos es la del sabio rodeado de una aureola de cabellos blancos, rico en experiencia y venerable, dominando desde muy alto la condición humana; si se apartan de ella caerán en desgracia: desaparecerán de la humanidad y de los textos, como veremos sucede en el período que abarca alrededor de treinta años a partir de la década de 1960, donde se transmitirá una imagen deficitaria de la vejez.

\section{ENTRE LAS DÉCADAS DE 1940 Y 1950}

Este período se caracteriza por una permanente referencia hacia los valores nacionales, hacia las regiones del interior del país, como así también al contexto latinoamericano. También se observa un proceso de crecimiento de la infraestructura económica: obras públicas, empresas del Estado e industria nacional.

Comienzan a tener vigencia otros sectores sociales de la comunidad. En consecuencia, aparecen imágenes de abuelos obreros y jubilados (e), con lo cual desaparece de los libros de lectura la imagen del viejo mendigo, común a principios de siglo. El poema "Yo anhelo" (8) indica:

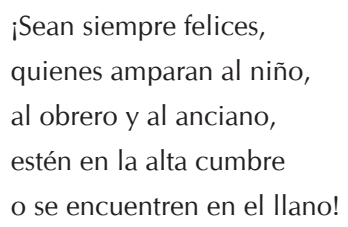

El tipo de familia predominante en la época continúa siendo la familia extensa, tanto a nivel rural como urbano, aunque en el libro Girasoles (9) se muestra a la familia nuclear, que tendrá vigencia a partir de la década de 1960 hasta la fecha.

Como en las épocas ya analizadas, la familia extensa se hace cargo de sus ancianos, lo que Ilamamos: "envejecimiento en familia", pero es en este período cuando aparece la imagen del "anciano institucionalizado", es decir que habita en un hogar de ancianos (10) Veamos el siguiente texto:

\footnotetext{
La abuelita

La abuelita de Tito y Susana es muy querida por su bondad. Cuando se puede -dice-, hay que ayudar a los demás.

La buena señora goza haciendo el bien. A menudo envía huevos, aves y verduras a los asilos y hospitales de la ciudad. (10 p.47)
} 
Y en la lectura "Enriqueta Veranito" (Figura 4), que es una estufa...

La vendieron a un asilo de ancianos. Allí sí que se acordaban todos de ella; todos los viejecitos a su alrededor calentaban sus manos y sus pies. ¡Que feliz vive ahora Enriqueta Veranito! (10 p.47)

La imagen que aparece con mayor frecuencia es la del abuelo. Este aparece en los textos brindando afecto a sus nietos y transmitiendo los valores morales imperantes en la época. Continúa la imagen del viejo como transmisor de la cultura, expresada en el período así: "la familia como sustentadora de la unidad nacional y de los pueblos, el estudio y el trabajo como sustentadores de la nación...". Este modelo es cumplido por los ancianos en otros roles, tal como "el viejo maestro".

Al mismo tiempo que aparece un anciano activo que debe y necesita ocupar su tiempo libre -no puede vivir sin trabajar- con una marcada valorización del trabajo (11 p.4) (Figura 5), aparece también la imagen del anciano minusválido que necesita de la ayuda y "debe ser ayudado" y protegido por los miembros de toda la comunidad (12).

-Abuelito -le dicen sus nietos-, usted no descansa nunca.

Y él les contesta:

-Yo no puedo vivir sin trabajar, chicos; el trabajo da alegría y salud al hombre; el trabajo es enemigo de la miseria, del vicio y de la tristeza. (11 p.4)

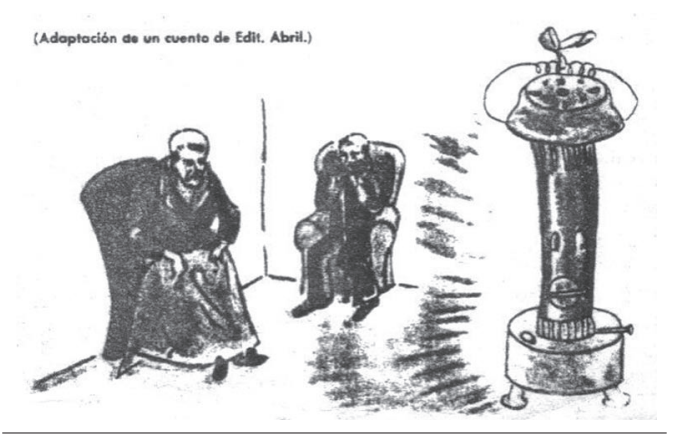

Figura 4. La vejez a fines de la década de 1950. Libro de lectura escolar Los teritos.

Fuente: Elma Elena Barbaglia, Edith Alina Barbaglia (10).

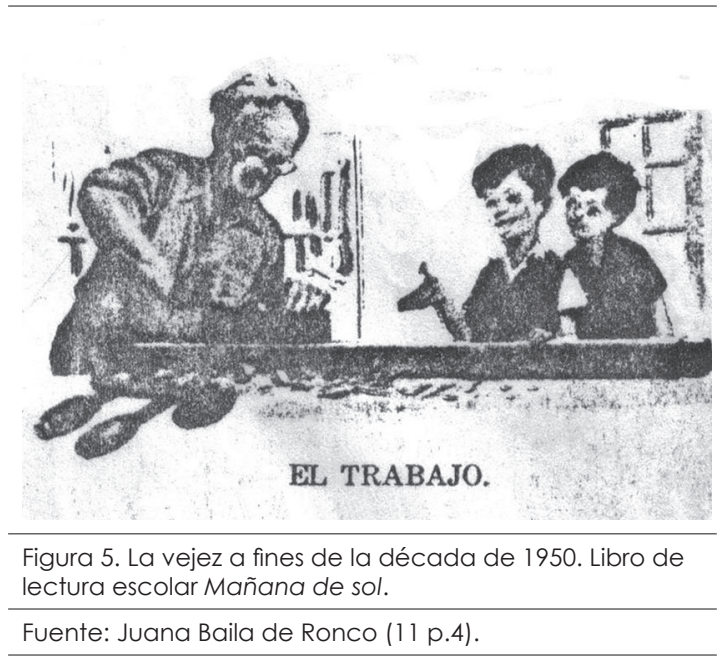

Las imágenes referidas se correlacionan con los contenidos de los puntos 1, 8, y 10 de los Derechos de la Ancianidad ( $\mathrm{f}$ ), vigentes en el momento histórico, cuyos temas son el derecho de la asistencia, al trabajo y al respeto, respectivamente. Recordemos aquí que los Derechos de la Ancianidad fueron presentados ante las Naciones Unidas en el año 1948, registrándose por primera vez el tema a nivel internacional, y fueron integrados en el texto de la Constitución Nacional del año 1949 (13).

En el período, las reflexiones sobre el tema de la vejez alcanzan a tener en cuenta la declinación física de los ancianos y la protección que se les debe dar (14). No se observa a la ancianidad como proyección futura de los niños -los ancianos son los otros-, no se habla de la muerte ni de la religión como trascendencia, como en el período anteriormente analizado.

En cuanto a la cantidad de apariciones, estas alcanzan un $10 \%$ del total de lecturas, por lo que para efectuar el análisis cualitativo hemos utilizado varios libros de textos.

Debemos señalar que en esta época los términos más utilizados para referirse al adulto mayor son anciano o abuelo; la palabra viejo suele tener una connotación peyorativa, veamos:

\section{Diferencias}

La ancianidad se venera.

La vejez se teme.

Decir viejo es referirse a la edad.

Decir anciano es significar: respeto, discreción, prudencia.

Un viejo puede ser un impío.

Un anciano es siempre virtuoso. (8) 
En este período suele utilizarse la palabra abuelo para referirse a los ancianos, incluso para aquellos que no cumplen con el rol familiar correspondiente.

\section{ENTRE LAS DÉCADAS DE 1960 Y 1990}

La década de 1960 se recuerda como un período de grandes cambios en el sistema de valores. Con relación al tema que nos ocupa, se observa una valoración de la juventud en sus aspectos externos (belleza física, modas, etc.).

Se transmite a los niños una cosmovisión "espacial" o "cósmica", una Argentina que es un trocito del planeta, una realidad que nos dice que el hombre llegó a la luna y que los niños se proyectan al futuro: "Era el año 3000 y la Tierra formaba parte de trescientos mundos habitados", dice la lectura " $\mathrm{ZP}=2$ " (15).

Es la era del espacio y de los cambios tecnológicos, adquieren importancia elementos como la tecnología y la investigación. En los textos aparecen imágenes de chicos que inventan, usan la química, se proyectan en un progreso sostenido.

En este contexto, el tema de la vejez no se encuentra incluido en la mayoría de los libros de lectura analizados y, en los que sí se incluye, las lecturas no suman más que una o tal vez dos por libro (g). Desde un análisis cualitativo, los "abuelos" cumplen un rol secundario, si bien son de "hecho" respetados y queridos por los niños, a quienes ellos miman. Aparecen como incapaces de cuidar o transmitir conocimientos a sus nietos, ya que suelen presentar problemas de audición, de vista o, peor aún, falta de criterios para la resolución de problemas o temas (Figura 6).

La familia es de tipo nuclear (h), por lo que ya no deciden en ella: los problemas familiares son tratados por los padres. El rol que se asigna a los ancianos es "familiar", "de abuelo", que solo van a visitar o son visitados por los nietos.

Las reflexiones sobre la vejez han desaparecido, también las enseñanzas sobre el respeto y protección que se les debe a los ancianos. Se ignora a la vejez en cuanto tal y, fundamentalmente, como cercana a la muerte.

En una cultura que tiende a cambios tecnológicos acelerados, que se proyecta a un futuro

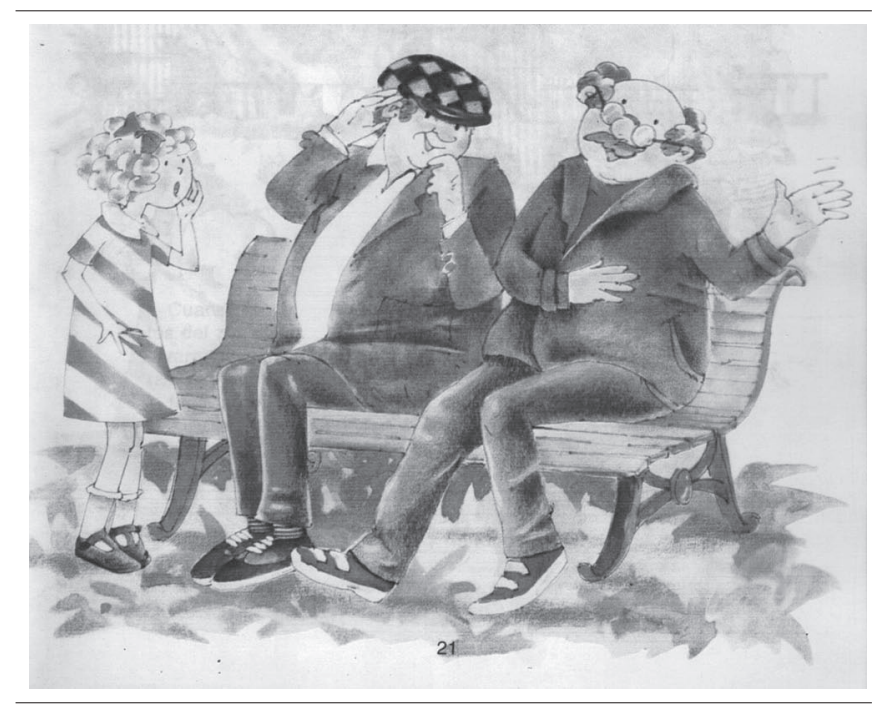

Figura 6. La vejez en la década de 1980. Libro de lectura escolar Los libros del Tamanduá, cuentos y cantos.

Fuente: María Teresa Forero (16 p.21).

espacial, los valores que los ancianos transmiten son desactualizados, por ello son reemplazados en esta función por modelos más jóvenes y actualizados: la tía o el tío.

Los ancianos han quedado en el período que se extiende de la década de 1960 a 1990 fuera del mundo de lo público, sin rol social que ejercer, siendo definidos por el familiar rol de abuelos situado en el mundo de lo privado.

\section{ENTRE FINES DEL SIGLO XX Y LOS PRINCIPIOS DEL SIGLO XXI (i)}

Como en el período anteriormente descripto, se transmiten los valores de una cultura tecnológicamente espacial y globalizada. Los chicos sobrevuelan el barrio dentro de un periscopio, por ejemplo. Al mismo tiempo el mundo de los personajes fantásticos se entremezcla con los personajes ligados al mundo real, construyendo la vida cotidiana en el contexto de un mundo ideal.

Coincidentemente con Bell (26) observamos que lo esencial para toda sociedad es su sistema de valores:

La moderna sociedad occidental ha dado importancia al crecimiento material y el incremento de la riqueza por encima de toda otra 
consideración. Pero esto ha traído también consigo muchos costos sociales. Ninguna sociedad puede ignorar el problema del equilibrio, dejar las decisiones esenciales enteramente al mercado o al dominio burocrático. Estos son algunos de los problemas más arduos de la teoría política actual, son juicios de valor, juicios comunales. Y la tecnología no ofrece respuestas, sea cual sea la ola sobre la cual avance. (26)

Lo que subyace detrás de las palabras del autor es la falta de paradigmas en la transmisión de los valores de la sociedad postindustrial que comienza a tomar conciencia de que la tecnología y el mercado no son suficientes para el desarrollo de un progreso económico-social sostenido y equitativo como parecía presentarse en períodos previos.

La construcción de la vida cotidiana a partir de un mundo ideal refleja esta falta de paradigmas orientadores de la acción social, en contraposición a lo observado en los períodos de principios del siglo XX hasta el inicio de la década de 1990 cuando el cambio social se establecía sobre principios orientadores definidos.

El análisis de los textos muestra -a partir de 1995- un cambio positivo con relación a la imagen de la vejez y de los roles que se asignan a los ancianos. En efecto, en los libros de lectura correspondientes a segundo grado se observa (producto del análisis cuantitativo) un incremento en el número de lecturas, que duplica o triplica el número de apariciones de personas de mayor edad con respecto al período anterior.

El rol de abuelo/a aparece en los diferentes textos estudiados en el marco de la familia nuclear, aunque se enseña a los niños el conocimiento sobre distintos tipos de organizaciones familiares tales como: familia extensa (propia de la historia de los antepasados), familias tribales (características de las comunidades aborígenes), y monoparentales y ensambladas. Estos abuelos a veces "vienen a colaborar con la familia", razón por la cual se les asigna nuevamente un papel activo dentro de ella, o bien, los nietos les escriben y les cuentan cosas.

La palabra don o doña reaparece en el contexto barrial al referirse a personajes como el verdulero o almacenero en algunos casos, o a un personaje querido como el de doña Muñeca.
Del mismo modo, reaparece la palabra viejo utilizada como sustantivo o adjetivo. Por ejemplo: “...Roque, el bibliotecario, era un viejito muy inteligente y amable" (20) o bien cuando se estudia en lenguas el tema de las rimas. Allí se expresa:

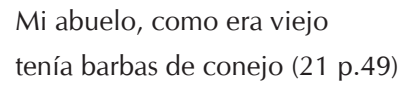

A partir del año 1995, los viejos vuelven a ser referentes para los chicos en un plano de igualdad con las otras generaciones que los "habían reemplazado" en el período anterior. Un ejemplo de ello se observa en la siguiente actividad: "Averigua como se prepara (un postre) y escribilo en tu cuaderno. [...] Preguntále a tu mamá, a alguna tía o a las abuelas" (21). O en una figura (para observar y sacar conclusiones) donde se muestra a Pedro, que es el abuelo de Joaquín, y el papá de Sergio. Los tres (están pescando juntos) son fanáticos de la pesca.

Los ancianos comienzan a integrar-además del rol familiar de abuelos- roles sociales, tal como lo hacían antes de la década de 1960. En este sentido, vemos que uno de los personajes centrales en el libro de lectura Patitas 2 (21), "Doña Muñeca", aparece reiteradamente a lo largo de las historias de los "paseadores de perros". Muñeca cumple y festeja sus sesenta años en el marco de estas historias, edad en que se inicia la vejez según la Asamblea Mundial sobre el Envejecimiento (27). La lectura "Chocolate para todos" es indicativa sobre esto:

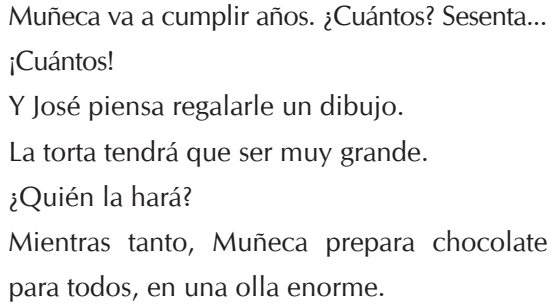

La imagen de viejo que presentan los libros de lectura analizados corresponde a personas de mayor edad activas y físicamente fuertes. Estas apariciones de ancianos que ocupan distintos roles, al igual que la reaparición de los vocablos don y viejo (utilizados en forma no peyorativa) en los textos, nos indica que se ha producido un 


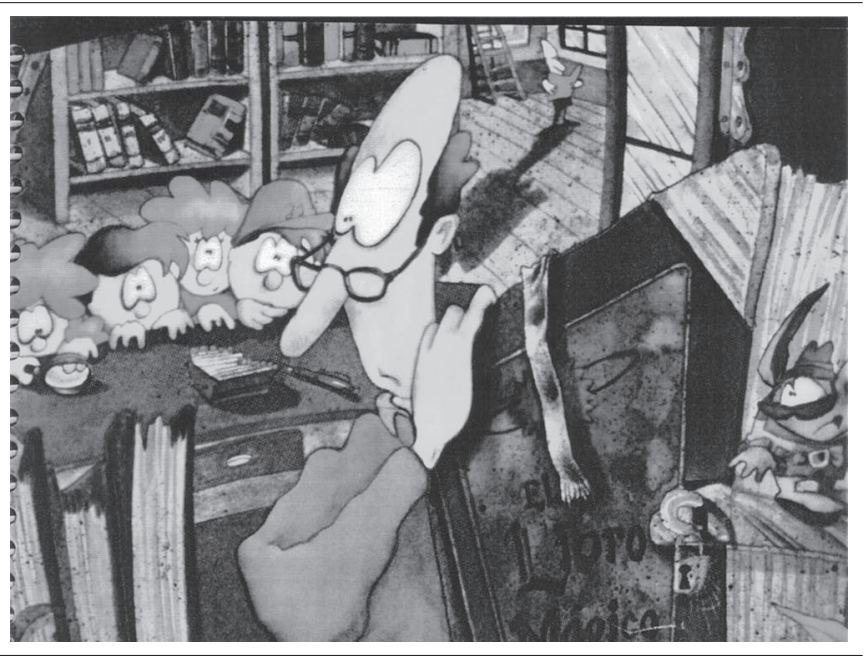

Figura 7. La vejez a fines de la década de 1990. Libro de lectura escolar Viajeros 2: Los detectives.

Fuente: Graciela Skilton (20 p.79).

cambio vinculado a la imagen de la vejez que la sociedad transmite a las nuevas generaciones. He aquí, en la Figura 7, la imagen de Roque, el viejo bibliotecario.

Estos cambios se irán consolidando a medida que avancemos hacia el siglo XXI. En efecto, se podrá observar en las historias de una familia cuyos padres son separados, el papel colaborativo de una abuela "vieja joven" en la crianza y cuidado de los niños cuando la mamá sale a trabajar, y también

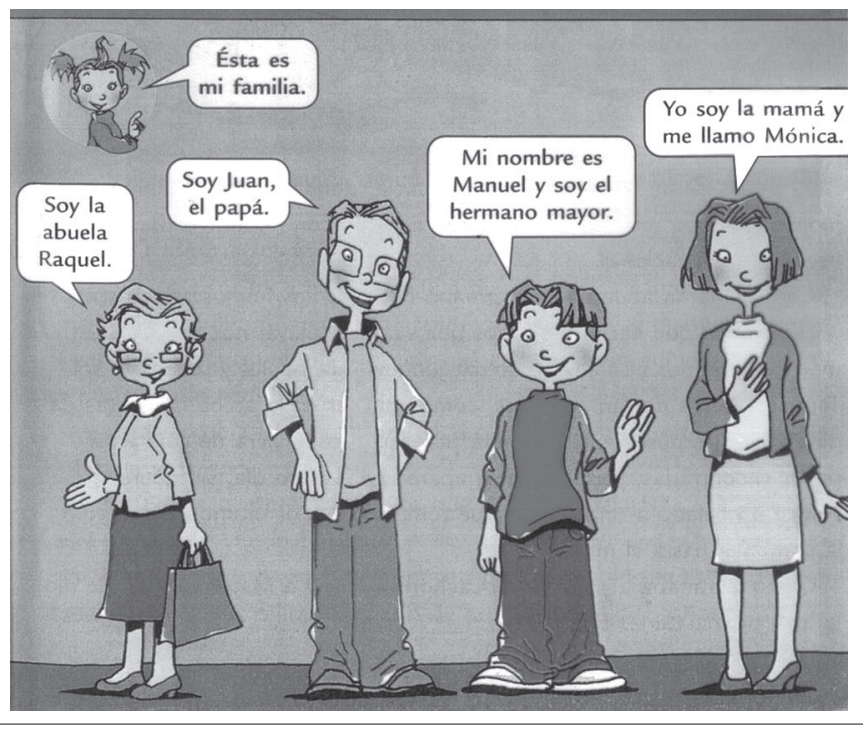

Figura 8. La vejez en la primera década del siglo XXI. Libro de lectura escolar Mauro y Emilia 2.

Fuente: Puerto de Palos (7). veremos que este mismo grupo sale de vacaciones con la abuela y no con el padre, dado que este no cohabita con el grupo familiar. Se puede observar que esta abuela tiene autoridad en la educación de los niños y sus amigos (Figura 8).

Es interesante observar cómo se registra en estos manuales el concepto de diversidad en la vejez y dan cuenta del incremento de la expectativa de vida de las sociedades actuales. Un indicador de ello es que por primera vez aparecerán los árboles genealógicos compuestos por cuatro generaciones. Los niños registran tener abuelos y bisabuelos en sus grupos familiares (Figura 9).

También, en el poema "Cumpleaños" de Jorge Accame, se registra la posibilidad de llegar a superar los cien años de vida para los seres humanos y, obviamente, hablamos de viejos-viejos:

\author{
Hoy día la abuela cumple \\ ciento diecisiete años. \\ Faltan velas en la torta porque se han terminado, \\ ya no hay más en la despensa \\ ni en el supermercado. \\ Hijos, nietos y bisnietos \\ corren, vuelan, preocupados. \\ ¡Vecino, présteme velas \\ que la fiesta es en un rato!... \\ (7 p.256) [cursivas añadidas]
}

Es así que en los albores del siglo XXI, al igual que en los albores del siglo $X X$, nuevamente se transmiten a los niños reflexiones sobre el proceso de envejecimiento, los intercambios de saberes entre las generaciones y el reemplazo entre estas. En la lectura "Sandía, maestro guardián" (7) se reflexiona sobre estos temas, mediatizados con la figura de un perro. Veamos:

Sandía era un perro ovejero que durante mucho tiempo había trabajado de guardián. Con los años su hocico se puso blanco, la frente se le arrugó, le costaba correr y se agitaba rápido, su ladrido no era tan potente como antes y tenía más sueño, cosa que lo puso remolón.

Un día su dueño trajo para reemplazarlo en su trabajo a un cachorro de nombre Hamburguesa, pues ya era hora que Sandía descansara. 
Pero un perro joven no conoce el trabajo de guardián. Por lo tanto, mientras el cachorro pasaba el día en juegos y en pedido de mimos a su dueño, y rompiendo y masticando zapatos, Sandía seguía con su tarea.

Ante este inconveniente, entendió que si quería descansar debía enseñarle su trabajo lo más rápido posible. Fue así que durante un tiempo Hamburguesa estudió con Sandía de maestro, las tareas de un buen perro guardián prestando atención a las enseñanzas y a todo movimiento del viejo instructor.

-Hamburguesa, el trabajo es muy sencillo. Cuando escuchás un ruido, te parás, alzas el pecho y levantas las orejas. Movés la cabeza y ladrás para demostrar que estás atento... [...] Hamburguesa aprendió su trabajo hasta convertirse en un gran guardián.

Se hizo cargo de la protección de la casa y así Sandía pudo, por fin, descansar.

Mucho tiempo después, cuando su hocico se puso blanco, su frente se arrugó, le costaba correr y se agitaba rápido, su ladrido no era tan potente como antes y tenía más sueño, cosa que lo puso remolón, su dueño trajo para reemplazarlo en su trabajo a un cachorro Ilamado Berenjena.

Cuando Hamburguesa lo recibió, lo primero que le dijo, luego de saludarlo, fue lo siguiente:

-El trabajo es muy sencillo, yo sé lo que te digo. Tuve la suerte de tener a un gran maestro.

Hamburguesa había comenzado a darle lecciones al cachorro, pues le llegaba, por fin, el tiempo de descansar.

(Ariel Galatro) (7 p.156-158)

Es decir, podemos ver en la lectura, mediatizada en este caso por la historia de los perros guardianes, el proceso de envejecimiento y la transmisión de conocimientos y valores entre las generaciones, en particular, de los viejos a los jóvenes.

Estos cambios coinciden con el crecimiento y la difusión de lo producido por las disciplinas que componen la Gerontología como producto de una sociedad cuyo proceso es precisamente el envejecimiento de sus poblaciones pero, al mismo tiempo, también pueden indicarnos que esta sociedad se encuentra en un período de transición

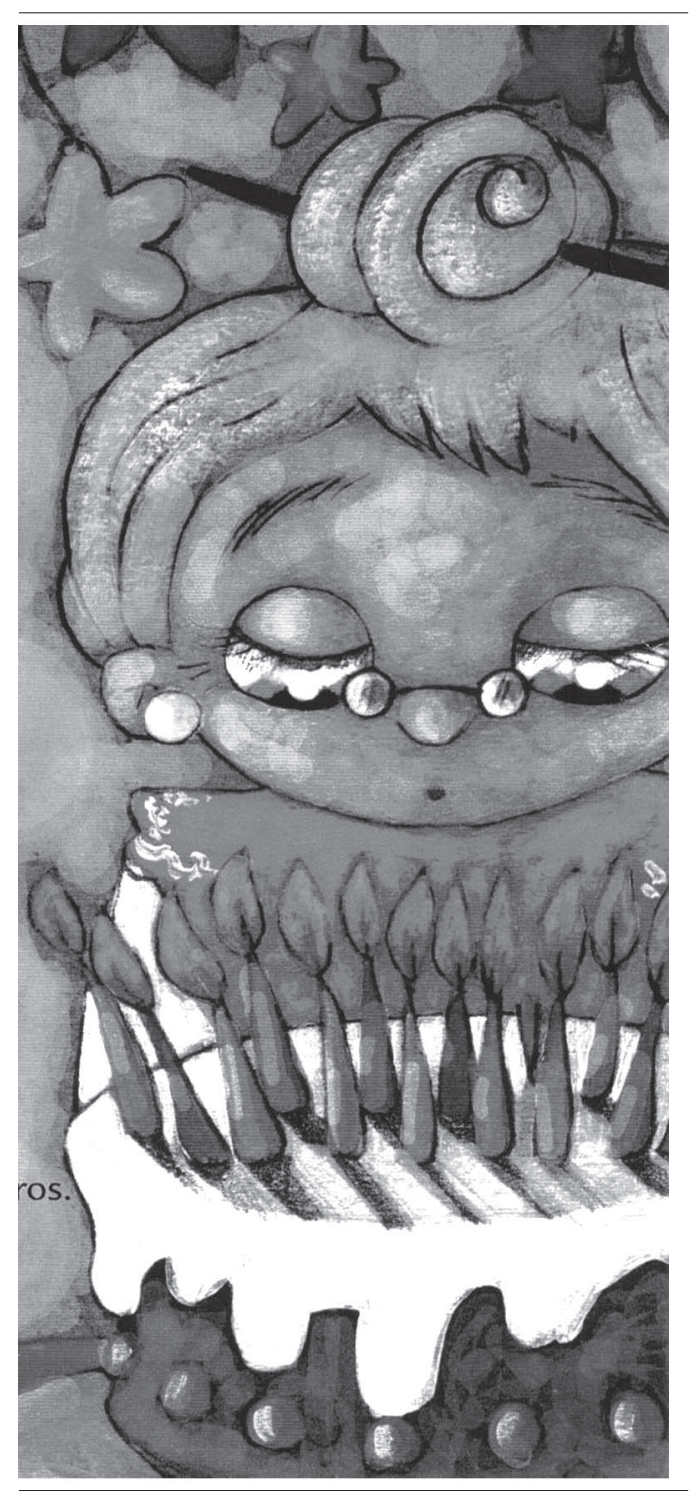

Figura 9. La vejez en la primera década del siglo XXI. Libro de lectura escolar Mauro y Emilia 2.

Fuente: Puerto de Palos (7).

producto de la insuficiencia del mercado y la tecnología para resolver los problemas sociales.

Según Minois, estos

...períodos llamados de transición conocieron un clima menos desfavorable a los viejos que los períodos de estabilidad, Ilamados "clásicos". Los tiempos de cambios profundos, liberados de los prejuicios y de las estructuras rígidas que caracterizan a los tiempos de equilibrio, están más abiertos a la diversidad de los talentos, más receptivos a la diferencia, menos cargados de los tabúes estéticos, morales o 
sociales. Se trata, sin duda, de períodos difíciles para todos, pero el anciano se ve en ellos menos rechazado; pues la precariedad es patrimonio común de todas las edades: el mundo helenístico, el tiempo de las invasiones germánicas y la baja Edad Media fueron menos duros para los viejos que la Grecia y la Roma clásicas o el Renacimiento. (6)

\section{CONCLUSIÓN}

A través de las lecturas de los libros de escuela primaria hemos recorrido el tiempo histórico que abarca desde fines del siglo XIX hasta el inicio del presente siglo. El papel asignado a los ancianos y la imagen de viejo que la sociedad argentina transmitió y transmite a las generaciones jóvenes, no ha sido lineal: cada período descripto tiene su propio modelo de anciano. Podemos notar como estos patrones se parangonan con los correspondientes a otros períodos históricos y contextos sociales (28 p.395-400). Así observamos a modo hipotético que:

- Los períodos más favorables a los ancianos son aquellos que se basan en la tradición oral, la experiencia y la costumbre. En ellos, los ancianos desempeñaron el papel de vínculos entre las generaciones y el de memoria colectiva (1880-1940). Por el contrario, los tiempos de aceleración de la historia contribuyeron a relegarlos a la categoría de lo viejo, de lo pasado de moda (1960-1995).

- Las sociedades más estructuradas (período conformado entre 1940 y 1950) donde el Estado y la ley tienen más autoridad para hacer respetar el orden, protegen más a los débiles de los "ataques" de los fuertes y la condición de los viejos será más favorable que en las sociedades más anárquicas basadas en la ley del más fuerte.

- Las sociedades que practican el culto a la belleza corporal tienden a menospreciar a la vejez (j), en tanto que aquellas que se rigen por un ideal estético más abstracto y simbólico dirigen su mirada hacia una belleza espiritual que está más allá de lo visible; por lo tanto serán más tolerantes con el envejecimiento de los actores sociales.

Por último, en los períodos transicionales (crisis de las sociedades globalizadas y flexibilizadas actuales) las sociedades tienden a igualar a todos los sectores sociales a partir de la inestabilidad que generan los cambios de patrones, favoreciendo la integración de los ancianos.

\section{NOTAS FINALES}

a. Para el presente análisis se utilizaron los libros El nene, de Andrés Ferreyra y José María Abuin (3), y Dos amigos, de Aurora Chiappe (4).

b. Recordemos la Ley Sáenz Peña donde el inmigrante con dos años de residencia podía emitir su voto, aun sin carta de ciudadanía. Por otra parte, un estudio realizado sobre el contenido de obras de teatro, nos indica que en el grotesco se desprende lo contrario a lo aquí expuesto.

c. Minois (6) se refiere a este tema para el período correspondiente a la alta Edad Media, cuando se veía la limosna como un deber pero destinada a asegurar la salvación del que da, más del que lo necesita, todavía no se habla del amor al pobre, y menos aún de su eminente dignidad. La ideología de la época implicaba la división de los hombres entre ricos y pobres, poderosos y débiles y así debía aceptarse.

d. Adelantando la exposición vemos que, en el período definido entre 1960 y 1990, aparece un nuevo personaje que no anula pero sí desplaza a los abuelos y es la tía o el tío.

e. Recordemos que en este período se establece el régimen jubilatorio argentino y se declaran los Derechos de la Ancianidad.

f. "Derecho a la Asistencia: Todo anciano tiene derecho a su protección integral, por cuenta y cargo de su familia. En caso de desamparo, corresponde al Estado proveer a dicha protección, ya sea en forma directa o por intermedio de los institutos y fundaciones creadas, o que se creasen con ese fin, sin perjuicio de subrogación del Estado o de dichos institutos, para demandar a los familiares 
remisos y solventes los aportes correspondientes. [...] Derecho al trabajo: Cuando el Estado y las condiciones lo permitan, la ocupación por medio de la laborterapia productiva, ha de ser facilitada. Se evitará así la disminución de la personalidad. [...] Derecho al respeto: La ancianidad tiene derecho al respeto y consideración de sus semejantes" (13).

g. Se utilizaron los siguientes libros de lectura: Los libros del Tamanduá, cuentos y cantos de María Teresa Forero (16); Páginas para mí de Zulema Cukier, Rosa María Rey y Beatriz Tornadú (17); Manantial de Blanca Brana de lacobucci y Juan P. Vitale (18); Dulce de leche de Carlos Joaquín Durán y Noemí Beatriz Tornadú (15); y Sol albañil de Ernesto Camilli (19).

\section{REFERENCIAS BIBLIOGRÁFICAS}

1. Oddone MJ. Los medios de comunicación social y la imagen de vejez: los libros utilizados en la escuela primaria. Medicina para la Tercera Edad. 1983;(1):24-32.

2. Oddone MJ. La vejez en la educación básica argentina. En: Salvarezza L, compilador. La vejez: Una mirada gerontológica actual. Buenos Aires: Paidós: 1998.

3. Ferreyra A, Abuin JM. El nene. 19 ed. Buenos Aires: Ángel Estrada.

4. Chiappe A. Dos Amigos. Buenos Aires: Maucci Hnos.

5. Cotta JM. Tierra hospitalaria. Buenos Aires: Peuser; 1937.

6. Minois G. Historia social de la vejez: De la antigüedad al renacimiento. Madrid: Nerea; 1987.

7. Puerto de Palos. Mauro y Emilia 2. Buenos Aires: Puerto de Palos Casa de Ediciones; 2005.

8. Burtin C. Del hogar a la escuela. Rosario: APIS; 1951.

9. Figun S, Moraglio E. Girasoles. Buenos Aires: Ángel Estrada; 1952.

10. Barbaglia EE, Barbaglia EA. Los teritos. Buenos Aires: Kapelusz; 1959.

11. Baila de Ronco J. Mañana de sol. Buenos Aires: Kapelusz; 1957. h. La familia nuclear es aquella compuesta por el matrimonio e hijos pequeños, no incluye a los abuelos.

i. Los textos utilizados son: Viajeros 2: Los detectives de María G. Gerini, Graciela Skilton y María A. D’Alessandría (20); Patitas 2: libro de lectura para segundo grado de Hebe Solves (21); Mauro y Emilia 2 de la editorial Puerto de Palos (7); Toni, Luli y Mili de la editorial Santillana (22); Antología de lecturas para 1er ciclo de Ediciones SM (23); Caramelos de coco y dulce 2 de la editorial Mandioca (24); Los edebits 2 de Gabriel Serafini, Gustavo Sposob y Graciela Ostrovsky (25).

j. Esto fue especialmente evidente en Grecia y en el Renacimiento (6).

12. Réboli I, Réboli D. Quiquiriquí. Buenos Aires: Kapelusz; 1944.

13. Convención Nacional Constituyente. Capítulo III Derechos del trabajador, de la familia, de la ancianidad y de la educación y la cultura: Inciso III De la ancianidad. En: Constitución de la Nación Argentina. Buenos Aires: 11 mar 1949.

14. Oria JA. Nuestra América. Buenos Aires: Editorial Estrada; 1948.

15. Durán CJ, Tornadú NB. Dulce de leche: libro de lectura para cuarto grado. Buenos Aires: Ángel Estrada; 1979.

16. Forero MT. Los libros del Tamanduá, cuentos y cantos. Buenos Aires: Aique Grupo Editor; 1989.

17. Cukier Z, Rey RM, Tornadú B. Páginas para mí. Buenos Aires: Aique Grupo Editor; 1980.

18. Brana de lacobucci BN, Vitale JP. Manantial. Buenos Aires: Kapelusz; 1972.

19. Camilli E. Sol Albañil. Buenos Aires: Editorial Estrada; 1965.

20. Gerini MG, Skilton G, D'Alessandría MA. Viajeros 2: Los detectives. Buenos Aires: Asis; 1996

21. Solves H. Patitas 2: libro de lectura para segundo grado. Buenos Aires: AZ Editora; 1995.

22. Santillana. Toni, Luli y Mili. Buenos Aires: Santillana; 2010.

23. Ediciones SM. Antología de lecturas para 1er ciclo. Buenos Aires: Ediciones SM; 2011. 
24. Estación Mandioca. Caramelos de coco y dulce 2. Buenos Aires: Estación Mandioca; 2010.

25. Serafini G, Sposob G, Ostrovsky G. Los edebits 2. Buenos Aires: Edebé; 2009.

26. Bell D. Reflexiones al final de una era. Revista Claves de Razón Práctica. 1996;(68):2-12.
27. Naciones Unidas. Plan de acción internacional de Viena sobre el envejecimiento [Internet]. Viena: UN; 1982 [citado 10 feb 2013]. Disponible en: http://www.imsersomayores.csic.es/documentos/documentos/asamblea-planviena-01.pdf.

\section{BIBLIOGRAFÍA DE CONSULTA}

Alba V. Historia social de la vejez. Barcelona: Editorial Laertes; 1992.

Bentancor A. Distancias cercanas: la percepción de los niños sobre la vejez. III Congresso Iberoamericano de Psicogerontologia: Subjetividade, Cultura e Poder [Internet]. 2009 [citado $10 \mathrm{dic}$ 2012]. Disponible en: http://www.geracoes.org. br/arquivos_dados/foto_alta/arquivo_1_id-85.pdf.

Bois JP. Histoire de la Vieillesse. Paris: Presses Universitaires de France; 1994.

Daino L. Antropología y ancianidad. En: Knopoff R Oddone M, compiladores. Dimensiones de la vejez en la sociedad argentina. Buenos Aires: CEAL; 1991.

Fericgla JM. Envejecer: Una antropología de la ancianidad. Barcelona: Anthropos; 1992.

Fondation Nationale de Gérontologie. Les grandsparents, la vieillesse et la mort dans la littérature enfantine. Paris: FNG; 1985.

Gastrón L, Monchietti A, Oddone MJ. Representações sociais sobre homens e mulheres na velhice. En: Tura LFR, Silva AO. Envelhecimento e representações sociais. Rio de janeiro: Quartet, FAPERJ; 2012.

Gastrón L, Oddone MJ. Reflexiones en torno al tiempo y el paradigma del curso de la vida. Perspectivas en Psicología. 2008;5(2):1-9.

Granjel L. Historia de la vejez: Gerontología, gerocultura, geriatría. Salamanca: Universidad de Salamanca; 1991.
Hyde V, Gibbs I. A very special relationship: Granddaughters' perceptions of grandmothers. Ageing and Society. 1993;13(1):83-96.

Jorquera P. Vejez y envejecimiento: Imaginarios sociales presentes en los textos escolares oficiales del Ministerio de educación chileno. Revista Mad. 2010;(22):132-165.

Marks R, Newman S, Onawola R. Latecy-aged children's views of aging. Educational Gerontology. 1985;11(2-3):89-99.

Oddone MJ. Los medios de comunicación social y la imagen de vejez: El teatro nacional. Medicina de la Tercera Edad. 1984:30-40.

Oddone MJ, Lynch G. Las memorias de los hechos sociohistóricos en el curso de la vida. Revista Argentina de Sociología. 2008;6(10):121-142.

Oddone MJ. La teoría social del envejecimiento: Un análisis histórico. En: Barca R, compilador. La gerontología a través de una historia institucional. Buenos Aires: Centro de Día; 2010. p. 50-62.

Oddone MJ, Lynch G. Memoria e impacto de la crisis de 2001 en las biografías individuales: Argentina en el cambio de siglo. Societal and Political Psychology International Review. 2010;1(2): 37-53.

Wainerman C, Heredia M. ¿Mamá amasa la masa?: Cien años en los libros de lectura de la escuela primaria. Buenos Aires: Editorial del Belgrano; 1999.

Zarebski de Echenbaum G. Lectura "teórico-cómica" de la vejez. Buenos Aires: Tekné; 1990.

\section{FORMA DE CITAR}

Oddone MJ. La vejez en los textos de lectura de la escuela primaria: un recorrido entre fines del siglo XIX y los inicios del siglo XXI en Argentina. Salud Colectiva. 2013;9(1):27-40.

Recibido el 21 de diciembre de 2012

Aprobado el 28 de marzo de 2013 